\title{
Features and Behavior of Submicrometer Aerosol Particles in the Urban Atmosphere of Nagoya
}

\author{
By Kikuo Okada*, Yutaka Ishizaka and Takao Takeda \\ Water Research Institute, Nagoya University, Chikusa-ku, Nagoya 464, Japan \\ (Manuscript received 20 March 1986, in revised form 19 June 1986)
}

\begin{abstract}
Number-size distribution of submicrometer particles was measured in the daytime in the urban atmosphere of Nagoya by using an electrical aerosol analyzer. It was confirmed that two characteristic types of size distribution reported by Okada (1985) appeared very often in the urban atmosphere of Nagoya. The occurrence of these distributions was discussed in association with the stages of gas-to-particle conversion and the speed of air passing over the urban area was concluded to be an important factor in the formation of these two distributions. The supersaturation spectra of cloud condensation nuclei $(\mathrm{CCN})$ were also measured on some occasions together with size distribution of particles.
\end{abstract}

\section{Introduciton}

In recent years a large amount of aerosol particles has been released from anthropogenic sources in the urban atmosphere. These particles, especially submicrometer particles, act an important role in the processes of radiative transfer and cloud formation in the urban atmosphere. The number-size distribution of submicrometer particles as well as their chemical composition is an essential factor to be taken into account in assessment of the effect of aerosol particles on atmospheric process.

On the basis of measurements in the urban atmosphere of Nagoya and Yokkaichi, Okada et al. (1983b) found that sulfate-containing particles were dominant with number fraction of 55 to $75 \%$ in particles of $0.016-0.28 \mu \mathrm{m}$ radius. They also pointed out that the numbersize distributions of submicrometer particles including those in the Aitken size range were closely related to the formation of sulfatecontaining particles by gas-to-particle conversion influenced by the amount of pre-existing

\footnotetext{
*Present affiliation: Meteorological Research Institute, Tsukuba, Ibaraki 305, Japan.
}

particles. Recently, Okada (1985) found two typical types of number-size distribution of submicrometer particles observed in Nagoya by electron microscopic examinations. However, the measurements were carried out only in few cases in summer. The extensive study of number-size distribution of submicrometer particles is required to assess the behavior of submicrometer particles in the urban atmosphere more clearly.

In the present study an electrical aerosol analyzer (EAA) was used to obtain the numbersize distribution of aerosol particles in various meteorological situations. The purposé of this paper is to confirm the occurrence situations of two characteristic types of number-size distribution of aerosols in the urban atmosphere, which were pointed out by Okada (1985), and to discuss them in relation to each stage of gasto-particle conversion. Some measurements of supersaturation spectra of cloud condensation nuclei (CCN) having two characteristic types of size distribution will be also indicated to demonstrate the meteorological significance of each distribution of aerosols. 


\section{Method}

Nagoya is one of large cities of Japan and it is located near the sea. Many anthropogenic sources are distributed in Nagoya and its surrounding area (Fig. 1). The atmosphere over Nagoya is influenced by the emission of aerosols and gases from these sources and the invasion of maritime air (Okada et al., 1983a). Measurements of number-size distribution of aerosol particles and light scattering coefficient were performed at Nagoya University, which is located on a hill in the eastern part of Nagoya city.

The number-size distribution of particles with radii between 0.005 and $0.28 \mu \mathrm{m}$ was measured with an electrical aerosol analyzer (EAA) (Thermo-systems Inc., Model 3030) on the condition of relative humidity lower than $65 \%$. Particles are first introduced into the charger of the EAA. After particles become electrically charged, they enter the mobility analyzer. The currents owing to the charged particles passed through the analyzer are measured with an electrometer current sensor by varying voltage. On the basis of these measured values, number concentrations are evaluated in each radius range below $0.5 \mu \mathrm{m}$. The EAA was operated with a charging current of $10^{7}$ ions $\mathrm{cm}^{-3} \mathrm{~s}^{-1}$ and the number concentrations of particles were calculated by using the constants given by Liu and Pui (1975). However, the constant for particles in the radius range of $0.0158-0.0281 \mu \mathrm{m}$ would not be applicable, as pointed out by Whitby and Cantrell (1979) and Tohno et al. (1981). In the present study the number concentration of particles in this radius

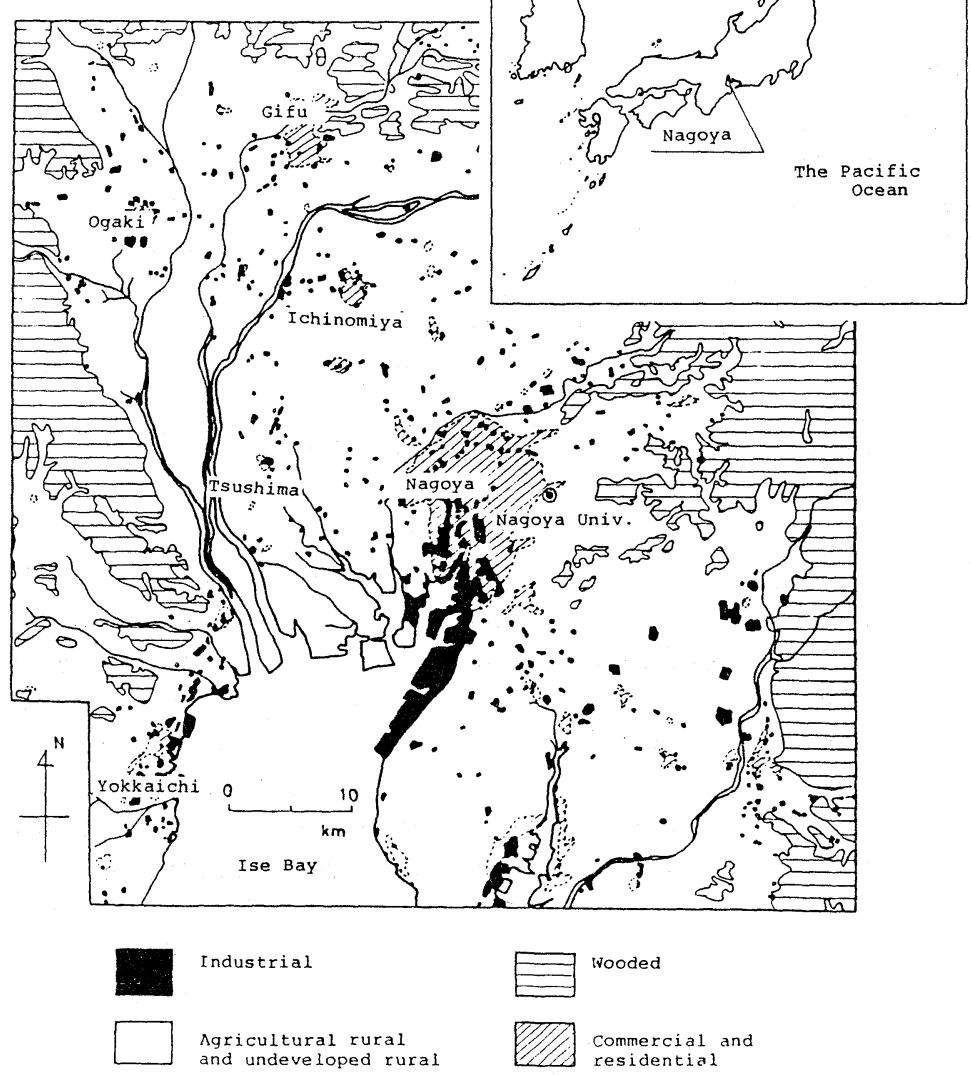

Fig. 1 Location of site. 
range was interpolated by using the concentrations of particles between 0.0089 and 0.0158 $\mu \mathrm{m}$ and between 0.0281 and $0.050 \mu \mathrm{m}$.

Light scattering coefficient was measured with an integrating nephelometer (Meteorology Research Inc., Model 1550B) on the condition of relative humidity lower than $50 \%$, in order to assess the amount of optically effective aerosols in dry conditions. The supersaturation spectrum of $\mathrm{CCN}$ was also measured on some occasions by using a cloud condensation nucleus counter (MEE Industries Inc., Model 130).

Meteorological data used in this study were obtained at Nagoya Meteorological Observatory, which is about $2 \mathrm{~km}$ away from Nagoya University.

\section{Time variations of aerosol number concen- tration and size distribution}

Figure 2 shows the time variations of the hourly integrated total radiation of sun and sky on a horizontal surface, number concentrations of submicrometer particles, light scattering coefficient and wind velocity during the period from 28 January to 22 February 1982. Particle number concentration was measured at $12: 45$ 13:00 LST and light scattering coefficient was measured at 13:00 LST. Hourly integrated radiation and wind velocity were observed at 12:0013:00 LST and 11:50-12:00 LST at Nagoya meteorological Observatory, respectively.

Light scattering coefficients ranged from 0.5 to $5.8 \times 10^{-4} \mathrm{~m}^{-1}$ during the observation period and they tended to decrease with increasing wind velocity. The number concentrations of particles with radii between 0.05 and $0.089 \mu \mathrm{m}$ and between 0.089 and $0.158 \mu \mathrm{m}$ changed with time in the similar way to light scattering coefficient. On the other hand, small particles of $0.005-$ $0.0089 \mu \mathrm{m}$ radius often showed concentration higher than $10^{4} \mathrm{~cm}^{-3}$. Their concentrations are inversely correlated with those of particles larger than $0.05 \mu \mathrm{m}$ radius, although they are slightly correlated to the intensity of the radiation. This suggests that the concentration of smaller particles was much influenced by the amount of larger particles.

One of the authors (Okada, 1985) found two typical types of number-size distribution in the atmosphere of Nagoya. Figure 3 shows the examples of two types of number-size distribution measured during the period shown in Fig. 2. Type A distribution exhibited a high number concentration of aerosol particles with radii less than $0.01 \mu \mathrm{m}$, more than $5 \times 10^{4} \mathrm{~cm}^{-3}$ in $\mathrm{d} N /$ dlogr. However, particles with radii larger than
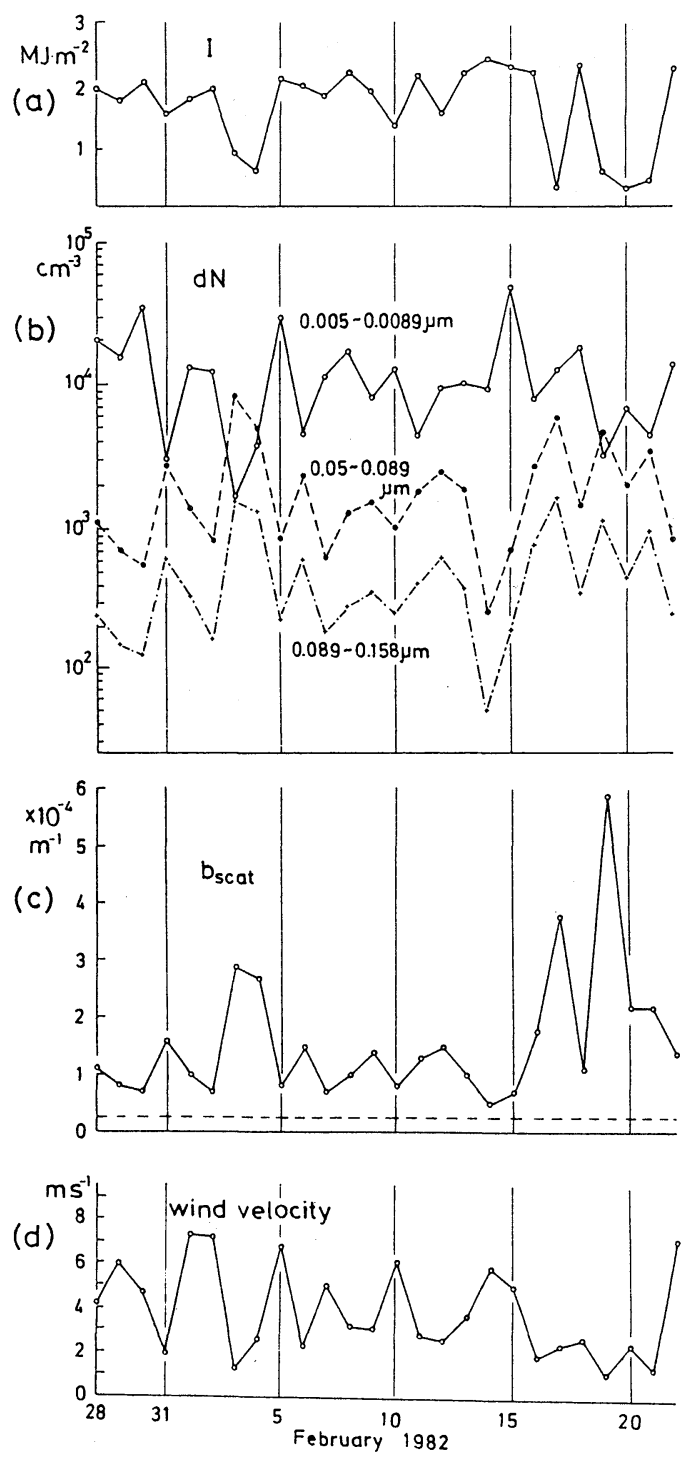

Fig. 2 Time variations of the hourly integrated total radiation of sun and sky on a horizontal surface (a), number concentrations of submicrometer aerosol particles (b), light scattering coefficient (c) and wind velocity (d) during the period from 28 January to 22 February 1982. The light scattering coefficient of air molecules is indicated by dotted line. 


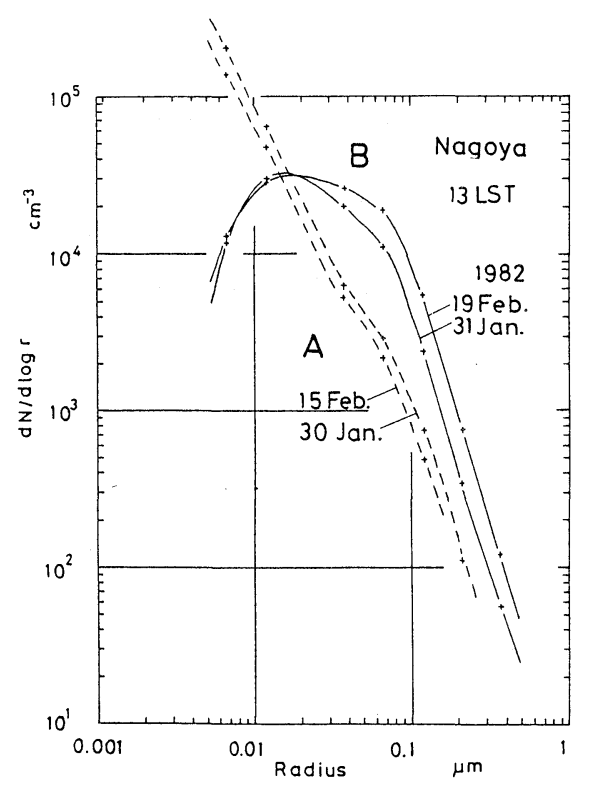

Fig. 3 Two characteristic types of number-size distribution (type A: dotted lines; type B: solid lines) observed during the period in Fig. 2.

$0.1 \mu \mathrm{m}$ are present in a concentration less than $10^{3} \mathrm{~cm}^{-3}$ in $\mathrm{d} N / \mathrm{d} \log r$. As seen in Fig. 2, this distribution was observed in relatively "clean condition" in which light scattering coefficient was less than $1 \times 10^{-4} \mathrm{~m}^{-1}$. Type $B$ distribution shows that aerosol particles with radii larger than $0.1 \mu \mathrm{m}$ are present in a concentration higher than $4 \times 10^{3} \mathrm{~cm}^{-3}$ in $\mathrm{d} N / \mathrm{dlog} r$. The concentration of aerosol particles with radii less than 0.01 $\mu \mathrm{m}$ seems to decrease with decreasing radius and it is lower than that in type A distribution. This distribution was observed in the situation of light scattering coefficient larger than $1 \times$ $10^{-4} \mathrm{~m}^{-1}$. Features of these two characteristic types of size distribution are consistent with those obtained by electron microscopic study in summer (Okada, 1985).

Figure 4 shows the relationship between the number concentration of aerosol particles of $0.005-0.0089 \mu \mathrm{m}$ radius $\left(N_{1}\right)$ and that of $0.05-$ $0.089 \mu \mathrm{m}$ radius $\left(N_{2}\right)$. Closed circles are the data in winter shown in Fig. 2a and open circles are data obtained at 11:45-12:00 LST in summer (30 July to 8 August in 1981). Although data scattered rather widely, the number concentration of aerosol particles of $0.005-0.0089 \mu \mathrm{m}$ radius tends to increase with decreasing concen-

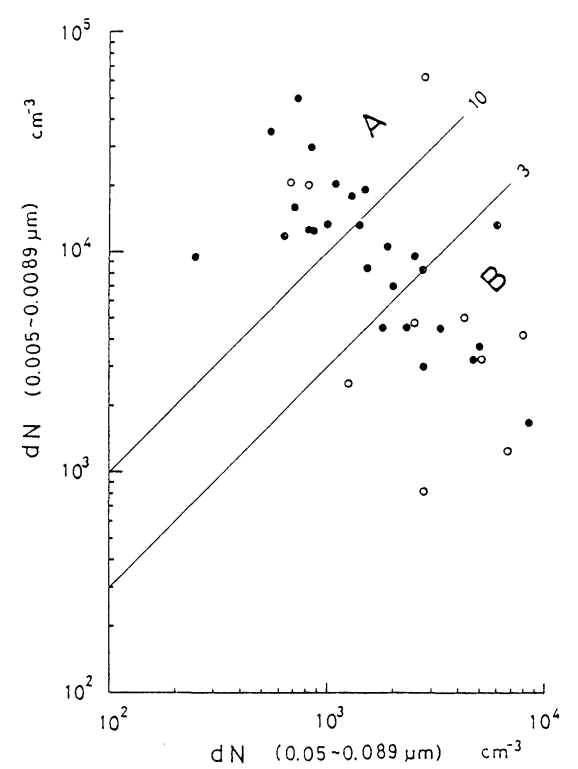

Fig. 4 Relationship between number concentration of aerosol particles of $0.005-0.0089 \mu \mathrm{m}$ radius and that of $0.05-0.089 \mu \mathrm{m}$ radius. Closed circles are data shown in Fig. 2b. Open circles are data measured from 11:45 to 12:00 LST in summer (30 July to 8 August 1981). Thin solid lines indicate $N_{1} / N_{2}$ ratios of 10 and 3 .

tration of aerosol particles of $0.05-0.089 \mu \mathrm{m}$ radius. No systematic difference seems to be recognized between the relation in winter and that in summer. Two solid lines in Fig. 4 indicate that $N_{1} / N_{2}$ ratio is 10 and 3 . The size distribution with $N_{1} / N_{2}$ ratio larger than 10 corresponds to A type and the distribution with the ratio less than 3 is $B$ type. It is to be noted that two types of size distribution pointed out by Okada (1985) were very often observed in the urban atmosphere of Nagoya and the size distributions of intermediate feature between two types also appeared though not frequently in the present study.

Figure 5 shows the frequencies of wind velocity at 12 LST when type A and B distributions were observed in Nagoya. The EAA data used in Fig. 5 are those measured in winter and summer. As seen in Fig. 5, more than $90 \%$ of type A distributions were observed in the situation of wind stronger than $3 \mathrm{~m} \mathrm{~s}^{-1}$. On the other hand, type $B$ distributions were present in the situation of wind velocity less than $3 \mathrm{~m} \mathrm{~s}^{-1}$. It should be noted that type A and B distributions 

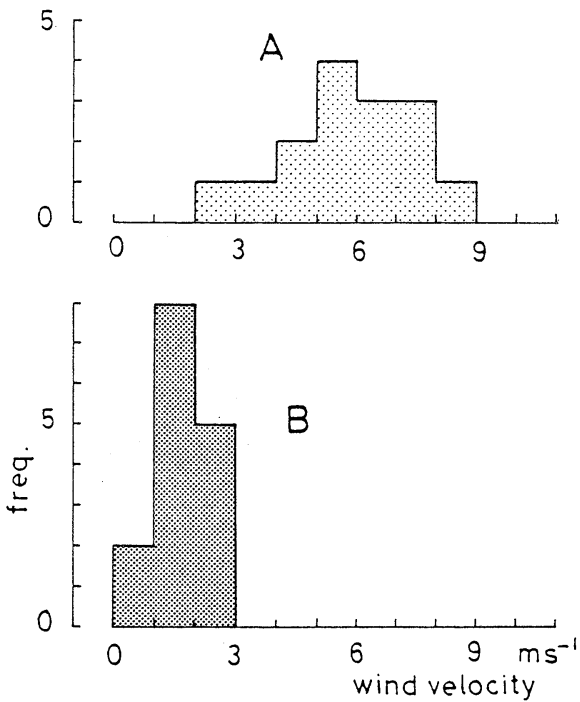

Fig. 5. Appearance frequencies of wind velocity when types $\mathrm{A}$ and $\mathrm{B}$ of number-size distribution were observed in Nagoya. EAA data used in this figure are those measured at 12:45-13:00 LST during the period from 28 January to 22 February in 1982 , and at 11:45-12:00 LST during the period from 30 July to 8 August in 1981 .

were observed regardless of wind direction.

4. Discussion on the formation of two characteristic types of number-size distribution

Although some of submicrometer particles are emitted primarily by the combustion of fossil fuels, most of them in the urban atmosphere are expected to be formed by gas-to-particle conversion (e.g., Gartrell and Friedlander, 1975). Kadowaki (1976) stated that sulfate and ammonium are the main constituents of submicrometer particles in the urban atmosphere of Nagoya and they were formed by gas-to-particle conversion. We will discuss the occurrence of two characteristic types of size distribution in Nagoya in relation to the formation of particles by gasto-particle conversion.

Formation of particles by gas-to-particle conversion has been studied in an initially particlefree chamber (e.g., Husar and Whitby, 1973; Kasahara and Takahashi, 1976). The schematic diagram of formation and growth of particles in Fig. 6 was produced on the basis of results by Husar and Whitby (1973) and Kasahara and Takahashi (1976). In the first stage, new particles are formed by molecular clustering of condens-

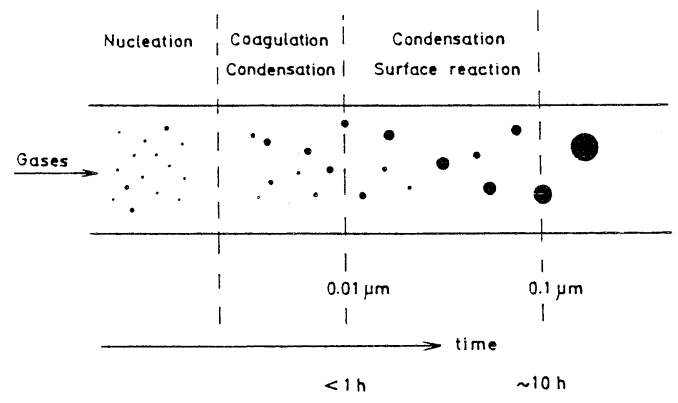

Fig. 6. Schematic diagram of formation and growth of aerosol particles in a flow reactor irradiated by light.

able molecules such as sulfuric acid molecules (homogeneous nucleation). This process leads to the initial sharp increase in the number concentration of small particles of about $10 \AA$ radius. In the second stage, total number concentration of particles reaches a maximum value and then it gradually decreases owing to coagulation process, which contributes to the formation of particles of $0.01 \mu \mathrm{m}$ radius. In order to assess the time required for the growth of particles, it is adequate to use the data concerning gas-to-particle conversion performed in particle-free urban air in the presence of solar radiation (Husar and Whitby, 1973). On the basis of their data, it would take less than 1 hour for new particles to grow to particles of $0.01 \mu \mathrm{m}$ radius. In the third stage, the formation of new particles by a homogeneous nucleation is hindered due to the consumption of condensable molecules by condensation on pre-existing particles. Heterogeneous processes such as the neutralization of acid particles by ammonia would be important in this stage. Though not shown in Fig. 6, particles other than those have formed by gas-to-particle conversion should exist in the actual atmosphere. Hence, heterogeneous processes on these particles would be also important to assess the behavior of submicrometer particles. Then, it is necessary to use the growth rate of particles by heterogeneous processes evaluated in the urban atmosphere. It is expected from the results obtained in the urban atmosphere of Nagoya (Okada, 1985) that the time required for the growth of particles from 0.01 to $0.1 \mu \mathrm{m}$ radius would be about 10 hours.

On the basis of these results we can hypothe- 


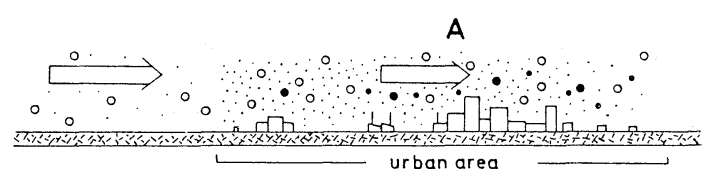

urban area

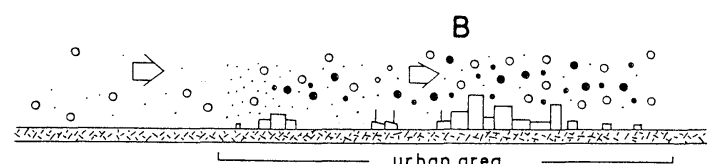

Fig. 7 Hypothetical model of the occurrence of types $A$ and $B$ of number-size distribution in the urban atmosphere in association with the difference in the velocity of air passing over the urban area. Particles with radii less than $0.01 \mu \mathrm{m}$ formed by a homogeneous nucleation are indicated by small dots.

-: particles originating from anthropogenic sources,

$\circ$ : particles entering from the outside of the urban area.

size that type A distribution is realized as a result of the initial stage of gas-to-particle conversion in the air mass moving rapidly over the urban area, and type B distribution appears in relation to the second or third stage of the conversion. This hypothetical model is shown in Fig. 7. After the air mass landed the urban area where anthropogenic sources are distributed, it travels over a long distance to the central part of Nagoya. The distance is simply assumed to be $30 \mathrm{~km}$ in following discussion.

In the situation of wind velocity of $5 \mathrm{~m} \mathrm{~s}^{-1}$, the air travels over a distance of $18 \mathrm{~km}$ for 1 hour after its landing and particles smaller than $0.01 \mu \mathrm{m}$ radius would be formed in it through a homogeneous nucleation. Though primary particles from anthropogenic sources are supplied into the air, the influence of these particles on the air would be small owing to the rapid movement of the air over the urban area. In this case vertical mixing of air would occur at a large rate and it may also lead to the decrease in the concentrations of particle surface area and condensable molecules which are important factors to control gas-to-particle conversion. Owing to a low surface area of particles in the air, formation of new particles should occur strongly in spite of relatively small concentration of condensable molecules. Though small particles would continue to be formed in the air through a homogeneous nucleation up to the observa- tion site in the center of Nagoya, the growth of new particles would be insufficient. Hence, particles formed by gas-to-particle conversion would be present mainly in the Aitken size range. This situation corresponds to the previous finding of Okada et al. (1983a) that sea-salt particles were often dominant particles of 0.2 $1 \mu \mathrm{m}$ radius in Nagoya in the case of a low light scattering-coefficient.

In the situation of wind velocity of $1 \mathrm{~m} \mathrm{~s}^{-1}$, the air travels for 8 hours to the observation site. In the first stage particles are formed through a homogeneous nucleation and type A distribution would be present. However, the air continues to be influenced strongly by the supply of primary particles from anthropogenic sources during its travelling owing to low velocity. A small vertical mixing of air would also influence the increase in the concentration of particles in the air. Large amount of pre-existing particles, which were supplied as primary particles or which were formed by gas-to-particle conversion, would suppress the formation of new particles by a homogeneous nucleation. Type B distribution, which has a high number concentration of optically effective aerosols, can be attributed to the formation and growth of particles in the second and third stages of gas-to-particle conversion and prohibiting effect of pre-existing particles on the formation of new particles.

\section{Remarks on the meteorological significance of two characteristic types of number-size distribution}

The aerosol particles of type $\mathrm{B}$ distribution will result in a high light scattering-coefficient and in the decrease in visibility and direct solar radiation in the urban atmosphere. On the other hand, the effect of type A distribtuion on the scattering of light is small in comparison with type B distribution. However, small particles in type A distribution might grow into large particles in being transported from the urban area to surrounding area and contribute to the increase in the amount of optically effective aerosols in places remote from air pollution sources.

Takeda and Kuba (1982) and Kuba and Takeda (1983) studied the effect of the size 
distribution and chemical composition of $\mathrm{CCN}$ on the size distribution of cloud droplets by numerical modelling. Their results show that the number concentration of $\mathrm{CCN}$ in the Aitken size range is a very important factor in deciding the major features of cloud-droplet size distribution such as number concentration, mean radius and width, and that it controls the production of large cloud droplets in a shallow cumulus cloud.

Thus it is interesting to examine the difference in $\mathrm{CCN}$ between two types of size distribution. Supersaturation spectrum of $\mathrm{CCN}$ was measured when two types of distribution were observed. Figure 8 shows the spectrum of $\mathrm{CCN}$ in the supersaturation range of $0.2-2 \%$.

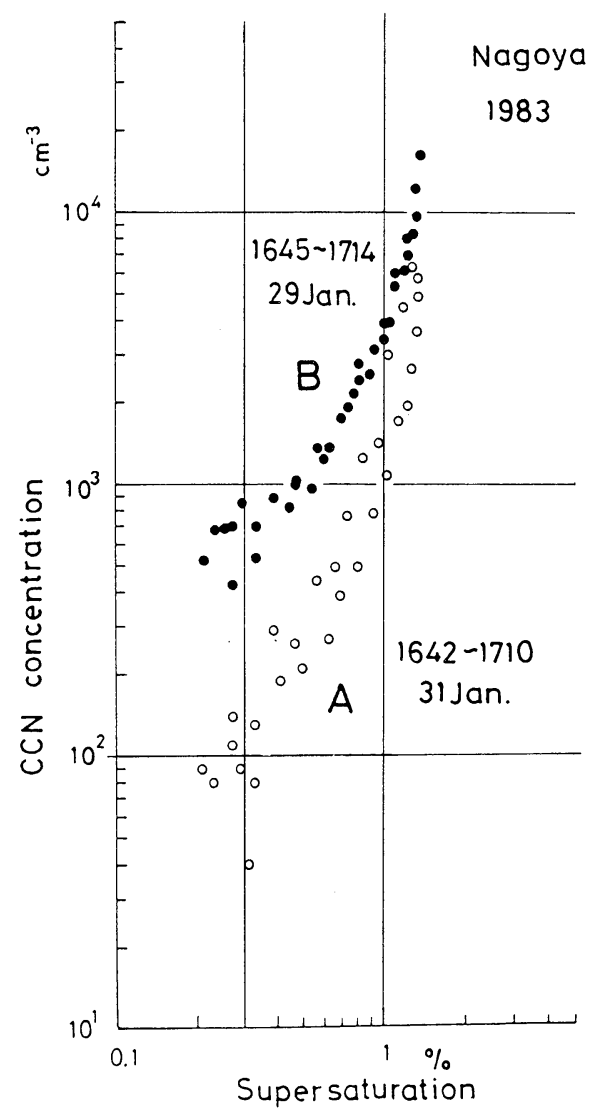

Fig. 8 Spectra of cloud condensation nuclei (CCN) measured in the supersaturation range of $0.2-2 \%$ when two characteristic types of number-size distribution were observed. Critical supersaturations of pure ammonium sulfate particles of $0.012 \mu \mathrm{m}$ and $0.048 \mu \mathrm{m}$ radius are $1.0 \%$ and $0.14 \%$, respectively.
The number concentration of $\mathrm{CCN}$ is higher in type $\mathrm{B}$ distribution than in type A distribution. The shape of CCN spectrum was different between both types, that is, the increasing rate of number concentration of $\mathrm{CCN}$ with supersaturation is larger in type A distribution than in type B distribution. Though physicochemical properties of particles would be also different between both types of distribution (Okada, 1985), the difference in the shape of spectrum would be mainly related to the difference in the number-size distribution between types A and B.

As shown in Fig. 8, the number concentrations of Aitken size $\mathrm{CCN}$ in type $\mathrm{B}$ distribution are higher than those in type A distribution in the supersaturation lower than $2 \%$. CCN in type A distribution would produce smaller number concentration and larger size of cloud droplets than those in type B distribution. On the other hand, $\mathrm{CCN}$ in type $\mathrm{B}$ distribution would produce a large number concentration of cloud droplets with small mean radius. Although the number concentration of $\mathrm{CCN}$ in the supersaturations lower than $0.2 \%$ was not measured in our study, it is suggested on the basis of the computational result of Kuba and Takeda (1983) that in former case, droplets formed on large CCN will contribute to the production of large cloud droplets by coalescence in a shallow cumulus cloud and in the latter case, giant $\mathrm{CCN}$ will be important in the production of large cloud droplets in the cloud.

In order to assess the effect of two characteristic types of distribution on the size distribution of cloud droplets in more detail, the spectrum of $\mathrm{CCN}$ should be measured, including those in the supersaturation lower than $0.2 \%$, together with the physicochemical properties of individual aerosol particles.

\section{Conclusions}

It was confirmed by the measurement of aerosol size distribution using an electrical aerosol analyzer (EAA) that two characteristic types of number-size distribution were very often observed in the daytime in Nagoya. In type A size distribution, optically effective aerosol particles with radii larger than $0.1 \mu \mathrm{m}$ were present in a low concentration. However, 
the number concentration of particles tended to increase strongly with decreasing radius in the Aitken size range and a pronounced high number concentration was found in the size range less than $0.01 \mu \mathrm{m}$ radius. Type A distribution was observed mainly in the situation of light scattering coefficient less than $1 \times 10^{-4}$ $\mathrm{m}^{-1}$. Type $\mathrm{B}$ distribution showed a high number concentration of particles in the size range larger than $0.02 \mu \mathrm{m}$ radius in comparison with that in type A distribution. This distribution was observed mainly in the situation of light scattering coefficient larger than $1 \times 10^{-4} \mathrm{~m}^{-1}$.

Wind velocity of $3 \mathrm{~m} \mathrm{~s}^{-1}$ was a criterion for the occurrence of two types of size distribution in Nagoya. Type A distribution appeared mainly in wind stronger than $3 \mathrm{~m} \mathrm{~s}^{-1}$. The occurrence of this distribution was considered to be closely related to the initial stage of gas-to-particle conversion in the air invading strongly into the urban area. On the other hand, type B distribution was observed on condition of wind velocity less than $3 \mathrm{~m} \mathrm{~s}^{-1}$. Its appearance would be attributed to the latter stage of gas-to-particle conversion in the air passing slowly over urban area. It is suggested that the speed of air passing over the urban area is an important factor in the formation of two characteristic types of size distribution in the daytime urban atmosphere.

In addition to the size distribution of aerosol particles, the supersaturation spectrum of $\mathrm{CCN}$ was measured. The number concentration of $\mathrm{CCN}$ in type $\mathrm{B}$ distribution was higher than that in type A distribution in the supersaturation range of $0.2-2 \%$. The increasing rate of number concentration of $\mathrm{CCN}$ in type A distribution was larger than that in type B distribution.

\section{Acknowledgements}

The authors are deeply grateful to Prof. A. Ono and Associate Prof. Y. Iwasaka, Water Research Institute, Nagoya University, for encouragement and helpful advice throughout this study. They also express their thanks to Dr. M. Misaki for useful comments on this study. This study was supported partly by Grant-in-Aid for Scientific Research, the Minitry of Education and Culture.

\section{References}

Gartrell, G., Jr. and S.K. Friedlander, 1975: Relating particulate pollution to sources: The 1972 California Aerosol Characterization Study. Atmos. Envir., 9, 279-299.

Husar, R.B. and K.T. Whitby, 1973: Growth mechanisms and size spectra of photochemical aerosols. Envir. Sci. Technol., 7, 241-247.

Kadowaki, S., 1976: Size distribution of atmospheric total aerosols, sulfate, ammonium and nitrate particles in the Nagoya area. Atmos. Envir., 10, $39-43$.

Kasahara, M. and K. Takahashi, 1976: Experimental studies on aerosol particle formation by sulfur dioxide. Atmos. Envir., 10, 475-486.

Kuba, N. and T. Takeda, 1983: Numerical study of the effect of $\mathrm{CCN}$ on the size distribution of cloud deoplets. Part II: Formation of large droplets. J. Meteor. Soc. Japan, 61, 375-387.

Liu, B.Y.H. and D.Y.H. Pui, 1975: On the performance of the electrical aerosol analyzer. J. Aerosol Sci., 6, 249-264.

Okada, K., 1985: Number-size distribution and formation process of submicrometer sulfate-containing particles in the urban atmosphere of Nagoya. Atmos. Envir., 19, 743-757.

, A. Kobayashi and N. Kuba, 1983a: Features of light scattering coefficient and aerosol particles in the urban atmosphere of Nagoya. Atmos. Envir., 17, 2087-2092.

- $\longrightarrow$, , Y. Iwasaka and T. Takeda, 1983b: On the number size distribution of Aitken particles in the urban atmosphere with regard to sulfate particles. J. Meteor. Soc. Japan, 61, 737-745.

Takeda, T. and N. Kuba, 1982: Numerical study of the effect of $\mathrm{CCN}$ on the size distribution of cloud droplets. Part I: Cloud droplets in the stage of condensation growth. J. Meteor. Soc. Japan, 60, 978-993.

Tohno, S., M. Itoh and K. Takahashi, 1981 : Estimation of aerosol size distribution by cascade impactor and EAA. J. Soc. Powder Technol. Japan, 18, 880-886 (in Japanese).

Whitby, K.T. and B.K. Cantrell, 1979: Electrical aerosol analyzer constants. Aerosol Measurement (Edited by D.A. Lundgren et al.), 492-493, University Press of Florida. 


\section{名古屋の都市大気におけるサブミクロン粒子の挙動と性状}

\section{岡田菊夫*・石坂 隆・武田喬男}

名古屋大学水圈科学研究所

日中において，名古屋の都市大気に浮遊するサブミクロン粒子の個数粒径分布をエアロゾル粒径分析 器（EAA）を用いて測定した。Okada（1985）によって報告された二つの典型的な粒径分布が頻繁に出現 することが確められた。がス一粒子変換過程の段階との関連でこれらの粒径分布の出現について議論し た結果，都市域上を通過する空気の速度がひとつの重要な因子であることが明かになった。また，二つ の典型的な粒径分布が存在した空気中での雲粒核過飽和度スペクトルについての測定結果も示した。

* 現在所属 : 気象研究所 